\title{
Telemedicine on the rise but lagging in Canada
}

- Cite as: CMAJ 2018 September 24;190:E1149-50. doi: 10.1503/cmaj.109-5634

Posted on cmajnews.com on Sept. 6, 2018.

W ith long waiting times and a shortage of family doctors, many patients are looking for an alternative way to access medical care. Private doctor-on-demand services are stepping in to fill the gap, even in countries with publicly funded health care, like Canada.

In the United States, telemedicine has taken off. In 2016, Kaiser Permanente, the country's largest integrated health network, conducted more consultations virtually than in person $-52 \%$ of 110 million visits were via online portals, virtual visits or apps. It found that patient outcomes were just as good with telemedicine, with no increase in misdiagnoses and a decrease in malpractice claims, as well as an increase in patient satisfaction.

The start-up company Doctor on Demand, which offers video-based telemedicine through an app, received US\$74 million in funding from investors such as Goldman Sachs to expand business. In the United Kingdom, it's been predicted that remote monitoring of conditions, virtual consultations and telemedicine will become the norm within a decade.

There are also several telemedicine companies in Canada, but the country lags most other nations, according to Dr. Brett Belchetz, CEO of Maple, a private telemedicine company based in Toronto. "There's this tremendous fear of telemedicine in Canada, as if it's something that's never been done," says Belchetz. "The truth of the matter is that it's been done for years, and incredibly effectively, in every other country."

Telemedicine companies have liability insurance to cover malpractice and the Canadian Medical Protective Association covers telemedicine.

Maple began offering physician consultations direct to consumers in 2016. It has about 200 physicians across the country.
The number of patients they see is "on par with a couple of busy walk-in clinics" each week, says Belchetz.

A similar service, called Akira, offers consultations primarily with nurse practitioners in four provinces, with national coverage expected soon. Akira's health professionals can write prescriptions, order tests and refer patients to specialists.

This convenience, however, comes at a price. Maple and Akira offer individual visits starting at $\$ 49$ and monthly subscriptions are available starting at $\$ 30$. Companies can purchase group plans as an employee benefit.
Some physicians are concerned that for-profit telemedicine goes against the universality principle of the Canada Health Act. And without access to a patient's medical records, telemedicine providers might not have enough information for diagnosis.

But most provinces don't fund telemedicine or provide little funding, so providers have to charge for services, says Belchetz. He likens it to laser eye surgery, a valid medical service the government decided not to cover. "We would love to be part of the public health system," he says.

Similarly, seeing a nurse practitioner is generally not an insurable service except

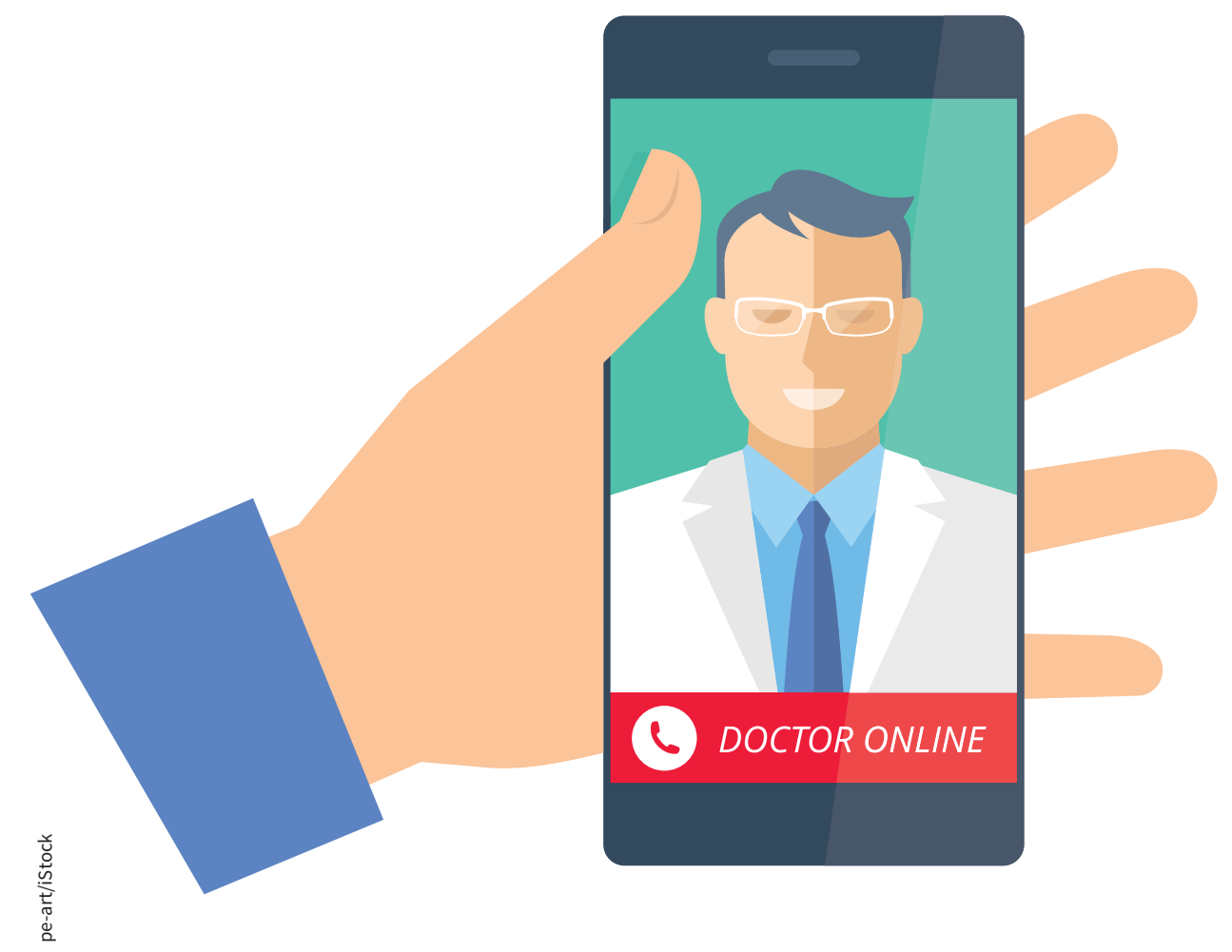

Want to talk to a doctor? There's an app for that. 
in specific practice environments. Meghan van Zanden, head of clinical operations at Akira, says the company is looking to partner with the public system to improve efficiency and patient outcomes.

Telemedicine companies are only prevented from charging for services available through the public system, says Dr. Sabrina Wong, director of the Centre for Health Services and Policy Research at the University of British Columbia. "They're simply filling a gap we can't fill adequately to meet the needs of the public," she says.
For doctors, telemedicine is attractive not just for the extra income, but because it is a pleasant experience, says Belchetz. Many of Maple's doctors are emergency physicians who take on consultations during their days off, or older physicians looking to slow down.

Not every medical problem can be dealt with via telemedicine. Physical examinations cannot be conducted. Wong says telemedicine works for a particular set of problems, such as urgent issues needing quick triage. "If they keep people out of the ER for minor problems, that's great."
Telemedicine works best when providers maintain relationships with patients, so those who provide initial consultations can follow up with patients for chronic disease management. This is Akira's model, says van Zanden. Their nurse practitioners follow up with patients on test results and can send notes to patients' family doctors if they have one. "We try to provide more continuity of care; we're not just a virtual walk-in clinic."

Brian Owens, St. Stephen, NB 